This is an Accepted Manuscript of an article published by Taylor \& Francis in Public Money \& Management on 28th January 2019, available online:

https://www.tandfonline.com/doi/full/10.1080/09540962.2019.1537705 


\section{Uncovering the practices of evidence-informed policymaking}

Louise Shaxson

\section{Abstract}

This article analyses two reports of efforts to strengthen evidence-informed policymaking within government departments; one from the UK and one from the USA. It reveals a series of specific evidence-related practices which share common purposes. These are assessed against Parkhurst's principles of the good governance of evidence. A suite of seven practices is identified that could form the basis for a holistic strategy to embed an evidence-informed approach to policymaking.

\section{Introduction}

The concept of evidence-based or evidence-informed policymaking has an established history in discussions of public policy (Albæk 1995; Cash et al. 2003; Parsons 2002; Radaelli 1995). A great deal of work has been done to improve the quality of evidence via, for example, 'What Works' centres (What Works Network 2014; Bristow, Carter, and Martin 2015) and to improve how evidence is communicated to policymakers in government departments (Nutley, Walter, and Davies 2007; Cherney et al. 2015). Complementing this is an increased understanding that the processes of informing public policy decisions with evidence are essentially political because of the need to incorporate multiple competing and changing social concerns (Cairney 2016, Parkhurst 2017) in conditions where the evidence is not just uncertain but often ambiguous (Cairney, Oliver \& Wellstead 2016).

But the literature has little to say about how the concepts derived from the academic literature have been made operational inside government. Much of the analysis has been written from the point of view of researchers (Newman, Cherney, and Head 2016), focusing 'primarily on the uptake of research evidence as opposed to evidence defined more broadly... privileging academics' research priorities over those of policymakers' (Oliver et al. 2014: 1). There are a few systematic reviews of the use of evidence in decision making but they focus on the use of research evidence (e.g. Orton et al. 2011) and the political and institutional factors that influence evidence use (e.g. Liverani et al. 2013).

Some empirical work does exist from developed countries (Howlett and Wellstead 2011; Wilkinson 2011; Vasileiou, Barnett, and Young 2012; Rosella et al. 2013; Zardo, Collie, and Livingstone 2014; Hyde et al. 2015) and the developing world (Paine Cronin \& Sadan 2015). However, it varies from ethnographic studies (Wilkinson) to studies which allow decision makers to articulate their own concepts of evidence and policymaking (Vasileiou et al., Rosella et al., Zardo et al, Paine Cronin \& Sadan) to studies which allowed some inductive reasoning about evidence within an overall conceptual framework (Hyde et al, Howlett \& Wellstead). There are no large-scale reviews of how evidence-informed policymaking is implemented inside government (Davies and Nutley 2002; Moore et al. 2016). 
This means there is little that can help us understand exactly what constitutes an improved approach to evidence-informed policymaking within government departments and how it is encapsulated in specific practices—-the 'materially-mediated activities' (Schatzki 2011: 20) which embody policy officials’ individual and collective understandings of what evidenceinformed policy is and how it is made.

This paper analyses attempts by central government departments in two jurisdictions (the UK and USA) to improve how evidence is used to inform decisions. It is not a comparative or an evaluative study; rather it uses evidence from two different cases to analyse what practices have developed inside government departments. The cases take the form of two documents: the 2014 Evidence Investment Strategy from the UK's Department for Environment, Food and Rural Affairs (Defra) and the 2016 federal What Works Index, published by the nongovernment organisation Results for America, which contains information about evidencerelated practices in seven federal departments and agencies. Both documents represent the culmination of several years' engagement with the debates around evidence-informed policymaking. In describing the specific practices that are being implemented they offer valuable empirical evidence of how and why different government departments have operationalised the concepts that have emerged from those debates.

But simply describing what government departments are doing is not enough: it is important to analyse to what extent this represents good practice. The framework used for this is Parkhurst's concept of the 'good governance of evidence' (Parkhurst 2017). This sets out eight principles to help ensure that both the quality of the evidence, and the quality of evidence-using decision processes, accord with an overarching ideal of good governance in public policymaking.

The paper proceeds as follows. The next section describes Parkhurst's principles of the good governance of evidence, which frame the subsequent analysis. The section on data and methods sets out the two cases and the methods used to uncover the evidence-using practices. The analytical section presents the detail of the practices that were uncovered in each document and groups them according to their common purposes. These are then analysed for alignment with Parkhurst's principles. Because there does appear to be a reasonable degree of alignment between the practices and the principles, the final section posits a suite of seven broadly-described practices that, if taken together, could form the kernel of a holistic approach to implementing evidence-informed policymaking inside a government department.

\section{Framing the analysis: from 'using evidence effectively' to 'the good governance of evidence'}

Using evidence effectively has been one of the core competencies of policymaking in the UK since the early 2000's (Bochel and Duncan 2007) though the phrasing has changed from 'using evidence effectively to 'making effective decisions' (Civil Service Human Resources 2012). Dealing with the challenges of incomplete and uncertain evidence, showing clarity of 
thought, minimising risks, evaluating and balancing different types of outcome are now seen as an integral part of the training of mid- and senior-level civil servants. But there is disagreement over what counts as good evidence (Oliver, Lorenc, and Innvær 2014; Cairney 2016). Evidence is managed and used in different ways (Weiss 1979; Sarewitz 2009; Daviter 2015) which vary across policy domains and organisational types (Head 2016). Thus the links between evidence and policy are in a constant process of negotiation (Parkhurst 2017).

Deciding what evidence is appropriate and good enough for each decision means decision makers must not only recognise and negotiate the multiple overlapping social concerns and contested outcomes that characterise policymaking processes (Stone 2002, Cairney et al 2016); they must also decide what methods for gathering, analysing and interpreting the various pieces of evidence are likely to be the most effective. These are shaped by the internal dynamics of each department, and by wider bureaucratic and political pressures such as civil service reform programmes, organisational cultures and internal structures and processes that influence how individuals and teams work with each other (references removed for blind review).

Themes of public sector reform, which include evidence informed policymaking, have changed over time from a relatively introverted approach to 'government' to a relatively extrovert approach to 'governance'. This involves many actors whose varying goals will change as public discourse changes, and who will harness information politically to support their arguments about ends and means as conflicts and compromises play out within wider policy environment (Head 2016; Stone 2002). Efforts to embed an improved approach to evidence must therefore recognise this more extroverted, political and processual approach to policymaking: focusing not only on 'the use of good evidence' but also on 'the good use of evidence' (Parkhurst 2017) or what Parkhurst calls ‘the good governance of evidence’. He argues that 'good evidence' accords to two normative principles of the evidence-informed policymaking movement: 'fidelity to science and usefulness' (ibid: 109). But 'good evidence for policy' has three other characteristics: it must address key policy concerns, be constructed in ways that help address those concerns, and be applicable to the local context (ibid: 123).

Parkhurst notes that the quality of evidence-related practices rests on the concept of legitimacy: ensuring that the various government bodies that use evidence in policymaking are democratically representative and responsive to the needs of the people they serve (input legitimacy), that they deliver effective solutions with the minimum of bias (output legitimacy) and that the processes they use encourage democratic deliberation by being transparent, accountable, inclusive and open to consultation (throughput legitimacy) (Schmidt 2013, and see Parkhurst ibid. pp141-142). This moves evidence-informed policymaking away from an overly technocratic 'deficit model' in which poor decision making is assumed to result simply from a lack of information (Wilsdon, Wynne, and Stilgoe 2005; Bauer 2009) towards a more engaged model which recognises the different ways problems are represented by different groups of people (Bacchi 2012; Hoppe 2002); the importance of public deliberation and democratic representation; and the inherently political nature of reasoned analysis (Stone 2002). 
The good governance of evidence can be summarised in eight principles (Parkhurst ibid., pp176-177):

- Appropriateness: evidence should be sourced, created and analysed in ways that help decision makers address multiple social concerns and local contexts;

- Quality: how evidence quality is judged should reflect the types of evidence being gathered as opposed to relying on a single hierarchy of evidence;

- Rigour: evidence should be rigorously gathered and interpreted to avoid cherrypicking;

- Stewardship: those who devise institutional arrangements to source and use evidence should have an official mandate and are accountable to the public;

- Representation: the authority to take final decisions about policies rests with 'democratically representative and publicly accountable officials' (p177), not unelected external bodies;

- Transparency: the ways evidence is used in decision making should be open and informative to the public;

- Deliberation: institutions should engage with the public around their multiple competing concerns and consider them throughout the decision process

- Contestability: there is an openness to critical questioning, both about the evidence that has been used and the processes through which it has informed decision making.

These principles are used here to analyse the practices of evidence-informed policymaking. If, in aggregate, practices intended to improve their use of evidence are aligned with the principles of the good governance of evidence, this would indicate the emergence of a holistic approach.

\section{Data}

Since 2013, Results for America, a non-profit organisation dedicated to supporting better evidence-informed decision making at all levels of government, has been working with federal departments and agencies to assess how well they have built the infrastructure needed to used evidence effectively for policy, budget and management decisions. The federal What Works Index (called 'the Index' for simplicity), which is published annually, assesses the extent to which seven federal agencies are using evidence to make management, budget and policy decisions. It uses ten criteria to make this assessment covering leadership, evaluation and research, resources, performance management and continuous improvement, data, common evidence standards, innovation, the use of evidence in decisions about different types of grant allocation, and repurposing resources away from failing policies or programmes (Results For America 2016).

The criteria have been developed and refined over the years via an expert consultative process with a wide range of government officials and academics. Each participating department or agency voluntarily submits information about what it does to improve how evidence is used. Results for America assesses this on a 5-point score, demonstrating a move 
from intent-to-meet to fully-and-successfully-meeting each criterion; giving the assessed organisations multiple opportunities to review and comment on the scoring and to provide further information where appropriate.

In 2014, the UK's Department for Environmental Affairs (Defra) published its third Evidence Investment Strategy (Defra 2014, referred to hereafter as 'the EIS'). This represented the culmination of approximately eight years of work to embed an evidence-informed approach to policymaking across the Department and its network of policy, advisory and delivery organisations (reference removed for blind review). The document sets out its priorities for sourcing evidence and the relationships it sought to build around evidence with partners such as other departments, Research Councils, industry, civil society and academia in the UK, EU and around the world. It articulates Defra's four aims for its evidence work: to maintain and improve access to evidence to meet policy and operational needs, to get the most from its investment in evidence, to drive up the quality of the evidence and the advice it provides, and to improve its preparedness and risk planning for both new policy priorities and potential threats (Defra 2014, p9). It identifies the different reasons it needs evidence: to identify and understand threats and opportunities; to inform policy and regulatory activity and operational development and delivery, to evaluate impact and value for money, and to stimulate innovation and growth. It also describes a framework Defra uses to allocate its evidence resources which distinguishes between strategic evidence (addressing longer-term, crosscutting and emerging issues), applied evidence (policy and operational issues) and statutory obligations (Defra is obliged to collect evidence to meet some UK or EU legal requirements). Underpinning this is the need to retain critical capabilities such as infrastructure, networks, expertise and data to ensure the department can respond to emergencies and to provide the cross-cutting capabilities needed to meet its ongoing objectives.

At 35 and 49 pages respectively, the Index and Defra's Evidence Investment Strategy provide a rich source of knowledge about what is being done to implement an evidence-informed approach in the different organisations; what practices are being used and for what purpose.

\section{Methods}

Following Schatzki (2001), practices are defined as sets of activities, mediated through social and material objects, which carry meaning and norms (Latour 2005); in this case meaning and norms around 'evidence-informed policymaking'. Practices, as contained in the documents, structures, staff positions, protocols and informal rules that codify them, play important roles in organisations - they communicate prior experiences (how and why things were done in the past), socialise new colleagues (to how and why things are done now), document successes and failures (what worked and what didn't) draw lessons (it would be better to do it this way), and communicate information about how the organisation behaves (Wilkinson 2011). Policy practices are not static: they evolve in response to a range of pressures from both within and outside the organisation (Mowles 2011; Nilsen 2015, Maybin 2016). Thus what is contained in the two documents is only a partial representation. However, they give an indication of how people within the departments describe and make 
sense of the evolving discourse around evidence-based policymaking. For example, the existence of an expert advisory committee with a remit to examine the quality of evidence does not guarantee that the evidence used in policy processes has improved. But it does signify that improving evidence quality is an important part of the discourse within the organisation and that practices are being implemented to operationalise its key aspects.

The analysis drew on theories of social constructionism (Burr, 2015) positing that practices emerge and change over time in response to the collective generation and regeneration of meaning about evidence-informed policymaking within government departments. In the absence of ethnographic research to understand how the discourses of evidence had developed on either side of the Atlantic, document analysis was used to interpret Defra's EIS and the detailed supplementary information provided for the Index; providing a snapshot of how those discourses had played out as of the dates the documents were published.

Document analysis is 'a process of evaluating documents in such a way that empirical knowledge is produced and understanding is developed' (Bowen 2009, p34); in this case empirical knowledge of what evidence-related practices were being used within government departments and an understanding of how they were being used. An initial scan of both documents confirmed that each contained multiple references to specific evidence-related practices such as staff positions, documents, organisational structures, processes, protocols, systems or norms (see Wilkinson 2011). It also revealed that the practices were referred to in different contexts. For example, 'frameworks' for using evidence were mentioned in relation to funding decisions, performance assessment, strategic planning, project design, investment decisions and risk planning. Although more documents are generally preferred for triangulation purposes, Bowen notes that what is more important is the documents' quality and the relevance of the evidence they contain to the purpose of the study (ibid). The number of references to different practices, and the different contexts in which they were mentioned, was felt to give sufficient richness for the more detailed analysis to proceed.

The second phase of the analysis involved close textual reading, looking for words and phrases that indicated an evidence-related practice. The initial search was purposefully kept open because of the potential for overlap between different types of practice. The word 'strategy', for example, could refer both to a document and the process that produced it. After the first close reading, key terms were developed to conduct the detailed search, ensuring that all possible expressions of each practice were captured. Key terms included, for example: analy* (analysis, analytical), budget, committee, expert* (expert/s, expertise), framework, manag* (manage, manager, management), partner* (partner/s, partnership, partnering), priorit* (priority, priorities, prioritisation), strateg* (strategy, strategic), network, official, plan* (plan/s, planning), program* (program/s, programme/s), and toolbox. The results were entered into a spreadsheet and grouped, as described in more detail in the next section. In four instances, internet searches were used to clarify issues mentioned in one of the documents but not described in detail. 


\section{Results}

The document review uncovered eight evidence-related practices in the Index and its supporting information, and eight in Defra's EIS document, as in Table 1 (that eight were found in each document was entirely coincidental).

Table 1: Evidence-related practices in the Federal What Works Index (2016) and Defra's Evidence Investment Strategy (2014)

\begin{tabular}{|c|c|}
\hline Document & $\begin{array}{l}\text { Evidence-related practices } \\
\text { (the terms are those used in each document) }\end{array}$ \\
\hline $\begin{array}{l}\text { Federal What } \\
\text { Works Index }\end{array}$ & $\begin{array}{l}\text { - Senior staff member with authority and oversight of evidence } \\
\text { - } \text { activities } \\
\text { - Existence of a budget for evidence } \\
\text { - } \quad \text { Comaluation policies and plans } \\
\text { - } \quad \text { Data sharing policies \& protocols } \\
\text { - Learning agenda around evidence } \\
\text { - Evidence dissemination tool } \\
\text { - } \quad \text { Performance management system that uses evidence }\end{array}$ \\
\hline $\begin{array}{l}\text { Defra's } \\
\text { Evidence } \\
\text { Investment } \\
\text { Strategy }\end{array}$ & 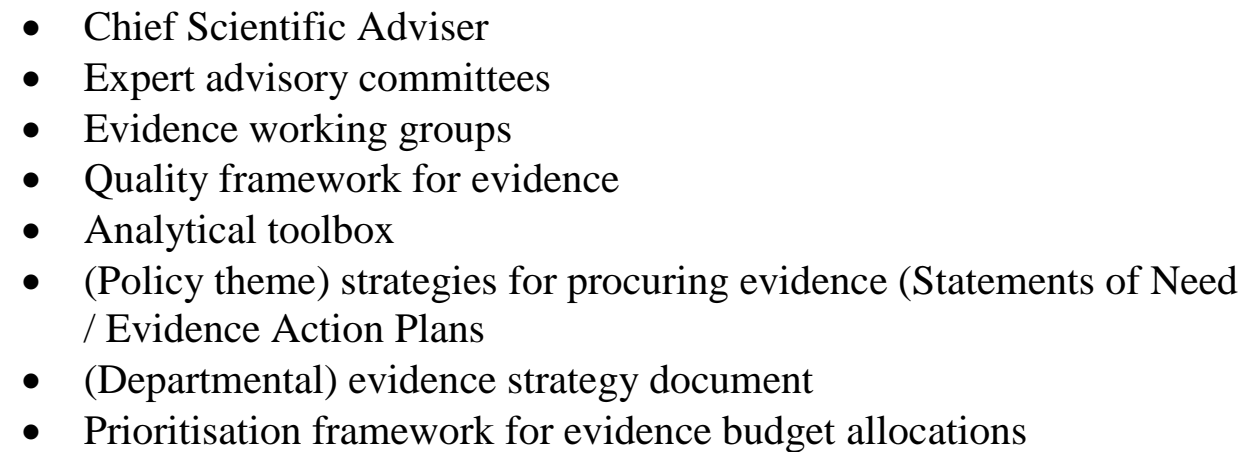 \\
\hline
\end{tabular}

The analysis initially set out to identify the individual practices, group them according to the types of activity they represented and then screen those groups against the principles of the good governance of evidence. However, what had been defined as a single practice could have more than one purpose. For example, both documents describe how people in positions of authority have several purposes: to advise political representatives, to take budget decisions, to demonstrate achievement and accountability, and to assure the quality of evidence. The analysis was thus expanded to explore the purposes in more detail.

Table 2 shows that seven purposes emerged as being common to both documents, each of which incorporated several different practices. These were: i) advising political leaders, ii) using evidence to strengthen decision making, iii) demonstrating achievement, efficiency and accountability, iv) managing the budget for sourcing evidence to inform policy decisions, v) building partnerships around evidence, vi) raising evidence quality, and vii) maintaining and developing capacity and capability for evidence 
Table 2: purposes and practices of evidence-informed policymaking in the Federal What Works Index (2016) and Defra's Evidence Investment Strategy (2014)

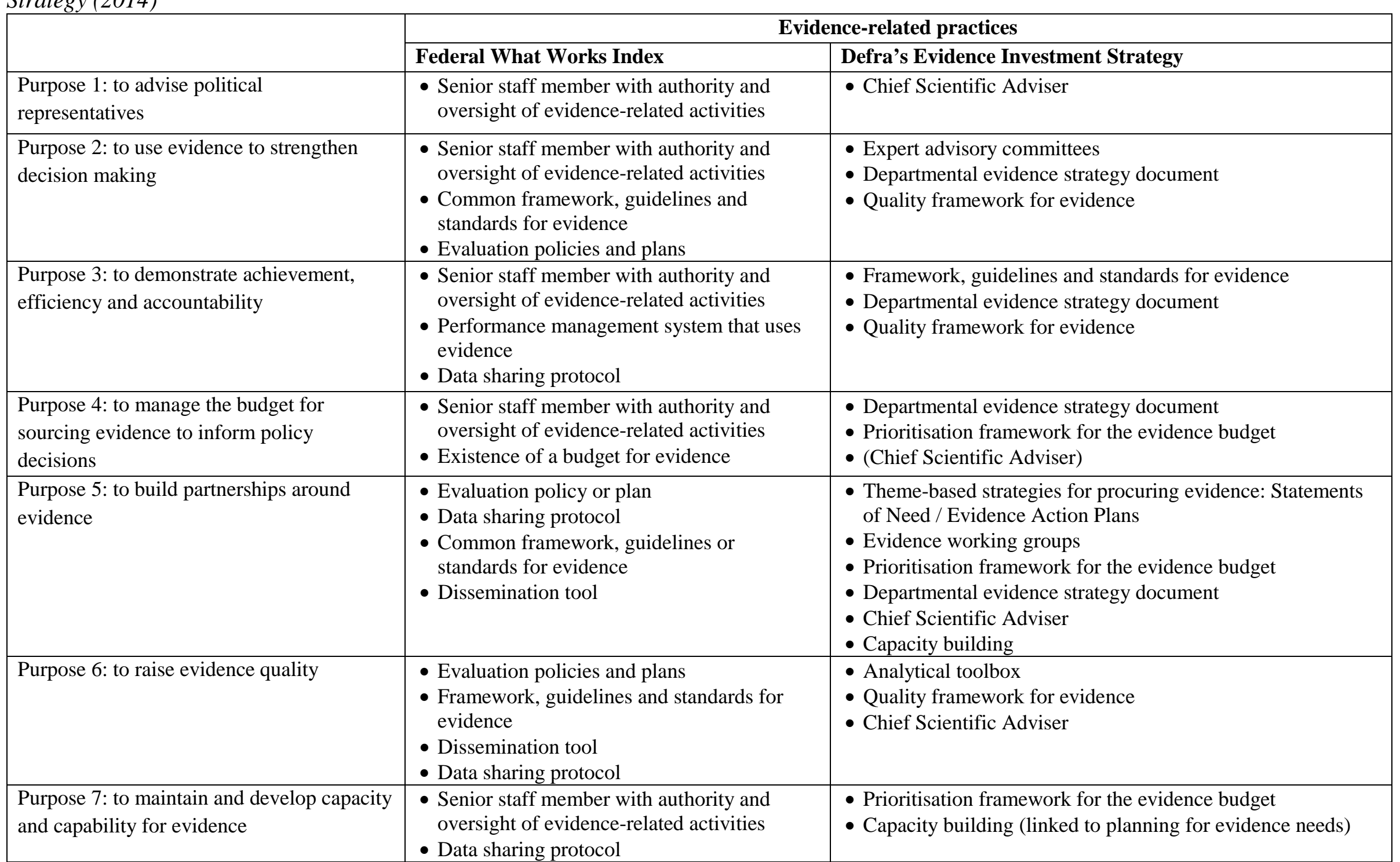


Given that the Index and Defra's EIS were unknown to each other, the fact that seven purposes emerged that are common to both documents suggests that the discourse around evidence in government is similar between the two jurisdictions. The analysis therefore shifted to whether, taken together, these seven purposes were aligned with the principles of the good governance of evidence. [Note that 'alignment' does not indicate that the practices within each purpose are sufficient to address all the principles in their entirety, simply that there is some degree of affiliation. More work would be needed to uncover exactly how aligned they are.] The rationale remained the same - to understand whether we can identify a group of practices that could form the kernel of a holistic approach to evidence-informed policymaking — but this interim step made the analysis more strategic; allowing a broad critique of how well the overall approach was aligned with Parkhurst's principles and where specific practices might be lacking.

\section{Analysing the alignment between purposes and principles}

Purpose 1: using evidence to advise political leaders

Both documents outline the need for a senior member of staff whose purpose is to advise politicians on the evidence to inform policy decisions and oversee evidence-related activities in the respective departments. In Defra, the Chief Scientific Adviser is responsible for providing Ministerial advice on the evidence base to inform policy decisions. Rather than a specific position, what emerges from the What Works Index is that this should be a senior official whose responsibility includes providing technical advice to Congress. This purpose and supporting practices appear to align with the principle of representation-that while the advice is given from within the bureaucracy, the ultimate authority to take policy decisions rests with elected representatives. It also aligns somewhat with the principle of stewardship in that both documents describe people with an official mandate to oversee evidence-related issues. But although Defra's Chief Scientific Adviser's remit covers public engagement and the current CSA stresses the need for openness, building mutual trust and respect (Boyd 2016), accountability to the public is not specifically mentioned in either document.

\section{Purpose 2: Using evidence to strengthen decision making}

In the Index, the federal agencies outline how the senior staff member (described above) uses evidence to inform and approve policy and programme design and budgeting, or to terminate underperforming programmes. All agencies covered in 2016 had specific evaluation policies and plans to gather evidence to feed into these decisions.

Defra's EIS discusses how the evidence strategy document itself demonstrates its commitment to high quality evidence. It does not outline any particular policy or programme approval process, but describes how its expert advisory committees provide oversight, assurance and constructive challenge to maximise the impact of evidence across all Defra's responsibilities. Such committees are not explicitly covered in the Index, but further analysis showed they are regularly employed by some federal agencies such as the Department of Labor, whose Advisory Committee on Increasing Competitive Integrated Employment for 
Individuals with Disabilities has a strong focus on the quality and use of evidence (Mank 2016).

Defra notes that it uses a quality framework to help make quality 'visible' to decision makers, to ensure that it is assessed consistently and to improve accountability-though does not specify how quality is defined. The Index specifically asks whether federal agencies have a common framework, guidelines or standards around evidence that inform project design and investment decisions. Responses from the seven agencies focus on ensuring definitional consistency and a consistent vocabulary around evidence: they discuss various quality issues such as the quality of evidence (associated with rigour, relevance, transparency and independence), quality of process (systematic, iterative, timely, forward-looking and ethical) and quality of engagement (a participatory approach).

Purpose 2 and its supporting practices appear to be aligned with the principles of quality, rigour and contestability.

Purpose 3: demonstrating achievement, efficiency and accountability The Index places a good deal of emphasis on using evidence for performance management purposes, consistent with its 'what works' ethos. Senior staff have the authority to evaluate major programmes and policy decisions, using evidence to shift funding away from consistently underperforming programmes. The Index also expects agencies to implement a performance management system with clear outcome-focused goals and to analyse return on investment and other dimensions of performance. All agencies covered by the Index had some form of data sharing protocol to help other entities at various levels of government to improve their performance.

Defra's EIS document does not explicitly discuss how it evaluates or otherwise assesses policy implementation, though further analysis showed that its in-house economists provide 'analysis, appraisal and evaluation for all aspects of Defra policy, to ensure policy decisions are informed by high quality and robust evidence in order to meet Defra's strategic objectives' (Defra, no date). However, its evidence quality framework is intended to improve accountability and visibility of quality for decision makers, and the EIS document indicates that Defra's approach to evaluating outcomes and demonstrating continuous improvement is embedded in other mechanisms such as lower-level strategy documents and plans.

Overall, this purpose and associated practices appear to align with the principle of appropriateness and the Index's emphasis on data sharing with the principle of transparency. Depending on how they are conducted and how the public engages with their results, the practices of policy and programme evaluation could also align with the principles of deliberation and contestability.

Purpose 4: managing the budget for sourcing evidence to inform policy decisions Both documents assume the existence of a specific budget for procuring evidence to inform decision making: either used wholly internally or in conjunction with budgets held by other 
organisations (such as research organisations). The Index outlines how the senior member of staff has authority to prioritise, negotiate and execute the budget for evidence projects including establishing a minimum percentage expenditure on evidence-related activities. Defra does not explicitly link budget management to the senior staff position, but the EIS document itself, which was led by the Chief Scientific Adviser, was seen as a tool to guide internal planning, prioritisation and delivery of evidence and Defra's budget prioritisation framework helps it maximise the value from investments in evidence, balance its statutory, short- and long-term needs, and guide internal planning around evidence.

Parkhurst's principles do not cover the concern, expressed in this purpose and its associated practices, with delivering value for money in managing departmental budgets for evidence. Value for money has become a key consideration for government departments (see for example HMG 1999; Mackay 2007; Head 2008; Head 2016) and is clearly still a distinct departmental focus in both jurisdictions.

\section{Purpose 5: building relationships around evidence}

Both documents describe practices that emphasise the need to work in partnership with others. Defra's EIS discusses its inter-organisational evidence working groups and the department's theme-based strategies and plans for procuring evidence, which are codeveloped with other agencies and public bodies linked to Defra's remit and lay out plans for how evidence needs will be met with partner organisations. The EIS document itself is described as being a statement of principles that could form the basis of discussion with partners, and a way of stimulating relationships with the research community.

The practices described in the Index offer less detail than Defra on relationship-building aspects, but several agencies set out how their evaluation policies and plans and data sharing protocols help leverage partnership opportunities.

Practices aimed at building relationships around evidence could align with the principles of deliberation, contestability, appropriateness and transparency - though clearly it would be essential to understand the detail of how and why those relationships are developed. Focusing these relationships on achieving outcomes (as in Purpose 3) could further enhance alignment.

\section{Purpose 6: raising evidence quality}

The two documents described 'evidence' in different ways. The Index notes evidence as coming from research or evaluations, reflecting its explicit focus on 'what works'. Defra defines evidence more broadly; sourcing it from research and development, statutory monitoring activities, secondary synthesis and analysis, and policy evaluations.

Both documents outline different practices used to raise evidence quality: Defra's 'analytical toolbox' is intended to ensure integrity and increase confidence in policy outcomes; the aim of its quality framework for evidence is to ensure a consistent assessment of quality. It notes that its Chief Scientific Adviser is responsible for ensuring quality and fit-for-purpose 
science. The practices outlined in the Index have similar aims: evaluation policies and plans should support adherence to departmental standards; similarly the common framework or guidelines around evidence quality should ensure definitional consistency and objectivity. Data sharing protocols are also mentioned as helping comply with, and improve, international data transparency standards.

This purpose and its associated practices align with the principles of quality and rigourdepending on how the analytical toolbox and quality framework is constructed (to explicitly encourage consideration of multiple contexts and social concerns) it may also align with the principle of appropriateness.

Purpose 7: maintaining and developing capacity and capability for evidence Both documents discuss the importance of developing capability and capacity for evidence. For the Index this comes through a learning agenda, a senior staff member whose remit is to build agency capacity, a data sharing protocol to encourage shared learning, and a learning agenda that emphasises different dimensions of evidence quality. Defra takes perhaps a more instrumental approach, noting that its evidence prioritisation framework helps it be flexible and outcome-focused, understanding how to sustain the critical capabilities necessary to fulfil its remit (for example, to manage future risks) and to support the development of new capabilities in response to emerging policy priorities.

Maintaining capacity and capability does not feature in Parkhurst's principles but emerges as a clear concern in both documents.

The overall alignment between principles and purposes is summarised in Table 3.

Table 3: alignment between the purposes associated with each evidence-related practice, and the principles of the good governance of evidence

\begin{tabular}{|l|l|}
\hline Purposes & Principles \\
\cline { 2 - 2 } $\begin{array}{r}\text { Purpose 3: demonstrating achievement, efficiency and } \\
\text { accountability }\end{array}$ & $\begin{array}{l}\text { Principles of the good } \\
\text { governance of evidence }\end{array}$ \\
$\begin{array}{l}\text { Purpose 5: building partnerships around evidence } \\
\text { making }\end{array}$ & Appropriateness \\
Purpose 6: raising evidence quality & Quality \\
\hline $\begin{array}{l}\text { Purpose 2: using high quality evidence to strengthen decision } \\
\text { Purpose 6: raising evidence quality }\end{array}$ & Rigour \\
\hline $\begin{array}{l}\text { Purpose 1: advising political representatives } \\
\text { Purpose 5: building partnerships around evidence }\end{array}$ & Stewardship \\
\hline Purpose 1: advising political representatives & Representation \\
\hline
\end{tabular}




\begin{tabular}{|c|l|}
\hline $\begin{array}{c}\text { Purpose 3: demonstrating achievement, efficiency and } \\
\text { accountability }\end{array}$ & Transparency \\
$\begin{array}{c}\text { Purpose 5: building partnerships around evidence } \\
\text { Purpose 6: raising evidence quality } \\
\text { accountability }\end{array}$ & Deliberation \\
$\begin{array}{c}\text { Purpose 3: demonstrating achievement, efficiency and } \\
\text { makpose 5: building partnerships around evidence }\end{array}$ & Contestability \\
\hline $\begin{array}{c}\text { Purpose 2: using high quality evidence to strengthen decision } \\
\text { Purpose 3: demonstrating achievement, efficiency and } \\
\text { Purpose 5: building partnerships around evidence }\end{array}$ & $\begin{array}{l}\text { Other issues not covered by } \\
\text { the principles }\end{array}$ \\
\hline $\begin{array}{c}\text { Purpose 4: managing the budget for sourcing evidence to } \\
\text { inform decisions }\end{array}$ & Value for money \\
\hline $\begin{array}{c}\text { Purpose 7: maintaining and developing capacity and } \\
\text { capability for evidence }\end{array}$ & $\begin{array}{l}\text { Maintaining capacity \& } \\
\text { capability }\end{array}$ \\
\hline
\end{tabular}

Clearly a great deal more work needs to be done to understand the detail of individual practices to flesh out this analysis, but overall, there appears to be enough alignment between the purposes and Parkhurst's principles to suggest that the beginnings of a holistic approach to evidence-informed policymaking have emerged on both sides of the Atlantic.

However, three issues emerged from the analysis. First, both documents emphasise the technical aspects of evidence-informed policymaking (aligned with appropriateness, quality and rigour) over issues of deliberation and public engagement (aligned with transparency, deliberation and contestability). Although the analysis focused on centre-of-government institutions that may not have a strong mandate to engage directly with the public, the question of how they incorporate public understandings into their policy development processes is an important one: both to frame policy problems and to debate their solutions. Public engagement is one of the defining features of Parkhurst's principles but it is not explicit in most of the practices. This suggests that careful attention needs to be paid to it, to reduce the risk of developing an overly technocratic approach to evidence-informed policymaking. However, defining public engagement as a discrete activity risks separating it from the main functions of the department, suggesting that it should be incorporated appropriately into existing practices rather than being addressed separately.

Second, both the EIS document and the Index have a strong message about value for money in how budgets are managed and outcomes are delivered, and the need for strategically managing departmental capability and capacity for evidence. Parkhurst's principles emerged from his exploration of two normative positions about evidence in policy processes: fidelity 
to science, and democratic representation (Parkhurst 2017). The analysis in this paper suggests that within government departments another normative position is also influentialeffective management of the human and financial resources that support evidence use. While more work needs to be done to explore this in detail, the analysis suggests that effective resource management should be retained as a separate concept that complements Parkhurst's principles.

Taking all of this together, is it possible to identify a minimum set of practices that would form the core of a holistic approach to evidence-informed policymaking? The analysis began by inductively drawing out the practices, identifying their purposes and then checking alignment with the principles. Working backwards from the breadth of the principles to the purposes and then to individual practices, it is now possible to suggest seven practices that are based on those common to the EIS and the Index but augmented to bring out the essence of Parkhurst's principles and the issue of effective resource management:

1. One or more staff positions with the authority, staff and budget to oversee an evidence-informed approach and the seniority to advise elected representatives on the use of evidence (representation, stewardship, effective resource management);

2. Independent expert advisory bodies with a remit to provide independent advice, scrutiny and challenge around the use of evidence to inform policy decisions and a similar remit to oversee the department's approach to public engagement around evidence (quality, rigour, transparency, contestability, deliberation);

3. Strategies, policies and plans at different levels which set out the priorities for evidence collection (appropriateness, quality, rigour, transparency, contestability, deliberation) and:

o Cover all types of evidence

o Demonstrate relevance to current and future policy directions and risks

o Are open and transparent to encourage public engagement around evidence

o Are updated, via broad-based engagement, on a regular basis

4. An open and transparent framework for prioritising budget allocations for evidencerelated activities and demonstrating value for money in how evidence is procured and analysed (transparency, effective resource management)

5. A suite of toolboxes, guidelines and analytical frameworks that strengthen the rigour and consistency of all types of evidence put forward for decision-making (quality, rigour, transparency);

6. A system of performance monitoring, reporting and evaluation that shows the value for money of how policy outcomes are delivered to citizens and demonstrates that resources are being allocated and reallocated based on evidence of effectiveness (appropriateness, stewardship, effective resource management);

7. A learning and competencies strategy which demonstrates a commitment to maintaining critical capabilities for evidence that are linked to key policy priorities, improving the use of evidence and encouraging innovation (quality, rigour, capacity and capability); 


\section{Conclusions}

This article set out to uncover what practices government departments are implementing and whether they represent a holistic approach to evidence-informed policymaking. Taking a broad definition of 'practices' to include staff positions, documents, protocols, activities, strategies and frameworks, two unconnected multi-year initiatives on different sides of the Atlantic were compared through detailed document analysis. The research uncovered a range of practices with shared purposes. Together they appear to have helped the departments covered in the analysis negotiate three normative positions around evidence: fidelity to science, democratic representation, and effective resource management.

The findings are, of course, only a snapshot. They reflect how the links between evidence and policy were negotiated in a limited number of government departments in two jurisdictions. They indicate how the formal aspects of the discourse around evidence were captured in policy documents. Much more research needs to be done to understand the detail of individual practices, how they evolved and what influenced that evolution. If we define practices as 'materially-mediated activities', we need to explore the politics of the mediation processes inside individual government departments and how the practices shaped, and were shaped by, the interplay of the three normative positions around evidence. But while the analysis is in its early stages, it does suggest that government departments and agencies concerned to implement a holistic approach to evidence-informed policymaking could consider basing their strategies on seven core practices. 


\section{References}

Albæk, Erik. 1995. "Between Knowledge and Power: Utilization of Social Science in Public Policy Making.” Policy Sciences 28 (1): 79-100. doi:10.1007/BF01000821.

Bacchi, Carol. 2012. "Introducing the 'What's the Problem Represented to Be?' approach.” In Engaging with Carol Bacchi: Strategic Interventions and Exchanges, edited by Bletsas A and Beasley C, 21-24. Adelaide: University of Adelaide Press. http://www.adelaide.edu.au/press/titles/engaging/engaging-ebook.pdf.

Bauer, Martin W. 2009. "The Evolution of Public Understanding of Science - Discourse and Comparative Evidence.” Science, Technology and Society 14 (2): 221-40. doi:10.1177/097172180901400202.

Bochel, Hugh M., and Sue. Duncan. 2007. Making Policy in Theory and Practice. Bristol: Policy Press.

Bowen, Glenn A. 2009. "Document Analysis as a Qualitative Research Method.” Qualtative Research Journal 9 (no.2): 27-40. doi:10.3316/qrj0902027.

Boyd, Ian. 2016. "What Is the Role of a Chief Scientific Adviser?” UKERC Network News. http://www.ukerc.ac.uk/network/network-news/guest-blog-what-is-the-role-of-a-chiefscientific-adviser-.html.

Bristow, Dan, Lauren Carter, and Steve Martin. 2015. "Using Evidence to Improve Policy and Practice: The UK What Works Centres.” Contemporary Social Science 10 (2). Routledge: 126-37. doi:10.1080/21582041.2015.1061688.

Burr, Vivien. 2015. Social Constructionism: Third Edition. Hove: Routledge. ISBN: 978-184872-191-3

Cairney, Paul. 2016. "Evidence-Based Best Practice Is More Political than It Looks: A Case Study of the 'Scottish Approach."” Evidence and Policy, 9-10. doi:10.1332/174426416X14609261565901.

Cairney, Paul, Kathryn Oliver and Adam Wellstead. 2016. “To Bridge the Divide Between Evidence and Policy: Reduce Ambiguity as Much as Uncertainty.” Public Administration Review 76 (3): 399-402. doi:10.1111/puar12555.

Cash, David, William Clark, Frank Alcock, Nancy Dickson, Noelle Eckle, David Guston, Jill Jäger, and Ronald Mitchell. 2003. "Knowledge Systems for Sustainable Development." Proceedings of the National Academy of Sciences 100 (14): 8086. doi:10.1073/pnas.0900541107.

Cherney, Adrian, Brian Head, Jenny Povey, Michele Ferguson, and Paul Boreham. 2015. "Use of Academic Social Research by Public Officials: Exploring Preferences and Constraints That Impact on Research Use” 11 (2): 169-88.

Civil Service Human Resources. 2012. “Civil Service Competency Framework 2012-2017.” https://civilservicelearning.civilservice.gov.uk/sites/default/files/Civil Service Competency Framework-A4-2012-2017_Level 4 - Grade 7 and 6 or equivalentHandout_Project Delivery.pdf.

Davies, Huw, and Sandra Nutley. 2002. "Evidence-Based Policy and Practice : Moving from Rhetoric to Reality.” 2. RURU Discussion Papers. http://www.ruru.ac.uk/pdf/Rhetoric to reality NF.pdf.

Daviter, Falk. 2015. “The Political Use of Knowledge in the Policy Process.” Policy Sciences 48: 491-505. doi:10.1007/s11077-015-9232-y.

Defra. 2017. "Research at Defra - Department for Environment, Food \&amp; Rural Affairs GOV.UK.” Research at Defra. Accessed September 13.

https://www.gov.uk/government/organisations/department-for-environment-food-ruralaffairs/about/research. . 2014. "Making the Most of Our Evidence: A Strategy for Defra and Its Network," 
no. June: $1-49$.

Head, Brian W. 2008. “Three Lenses of Evidence-Based Policy.” Australian Journal of Public Administration 67 (1): 1-11. doi:10.1111/j.1467-8500.2007.00564.x.

_ 2016. “Toward More ‘Evidence-Informed’ Policy Making?” Public Administration Review 76 (3): 472-84. doi:10.1111/puar.12475.

HMG. 1999. "Modernising Government.” http://www.archive.officialdocuments.co.uk/document/cm43/4310/4310-00.htm.

Hoppe, Robert. 2002. “Cultures of Public Policy Problems.” Journal of Comparative Policy Analysis: Research and Practice 4: 305-26.

Howlett, Michael, and Adam Wellstead. 2011. "Policy Analysts in the Bureaucracy Revisited : The Nature of Professional Policy Work in Contemporary Government." Politics \& Policy 49 (4): 613-33.

Hyde, J K, T I Mackie, L A Palinkas, E Niemi, and L K Leslie. 2015. "Evidence Use in Mental Health Policy Making for Children in Foster Care.” Administration and Policy in Mental Health and Mental Health Services Research, no. February. Springer US: 52-66. doi:10.1007/s10488-015-0633-1.

Latour, Bruno. 2005. Reassembling the Social : An Introduction to Actor-Network-Theory. Oxford University Press.

Liverani, Marco, Benjamin Hawkins, and Justin O Parkhurst. 2013. "Political and Institutional Influences on the Use of Evidence in Public Health Policy. A Systematic Review.” PloS One 8 (10): 9. doi:10.1371/journal.pone.0077404.

Maybin, Jo. 2016. Producing Health Policy: Knowledge and Knowing in Government Policy Work. London: Palgrave Macmillan. ISBN: 978-1137583925

Mackay, Keith. 2007. "How to Build M\&E Systems to Support Better Government." Washington DC. doi:10.1596/978-0-8213-7191-6.

Mank, David M. 2016. "Final Report of the Advisory Committee on Increasing Competitive Integrated Employment for Individuals with Disabilities.” https://www.dol.gov/odep/topics/pdf/ACICIEID_Final_Report_9-8-16.pdf.

Moore, Gabriel Mary, Sally Redman, Tari Turner, and Mary Haines. 2016. "Rapid Reviews in Health Policy: A Study of Intended Use in the New South Wales' Evidence Check Programme.” Evidence \& Policy: A Journal of Research, Debate and Practice 12 (4): 505-19. doi:10.1332/174426415X14446635524057.

Mowles, Chris. 2011. Rethinking Management. Farnham: Gower Applied Business Research.

Newman, Joshua, Adrian Cherney, and Brian W. Head. 2016. "Do Policy Makers Use Academic Research? Reexamining the 'Two Communities' Theory of Research Utilization.” Public Administration Review 76 (1). Wiley Subscription Services, Inc.: 24-32. doi:10.1111/puar.12464.

Nilsen, Per. 2015. "Making Sense of Implementation Theories, Models and Frameworks." Implementation Science 10 (1). BioMed Central: 53. doi:10.1186/s13012-015-0242-0.

Nutley, Sandra, Isabel Walter, and Huw Davies. 2007. Using Evidence : How Research Can Inform Public Services. Bristol: Policy Press.

Oliver, Kathryn, Theo Lorenc, and Simon Innvær. 2014. "New Directions in Evidence-Based Policy Research: A Critical Analysis of the Literature.” Health Research Policy and Systems / BioMed Central 12. BioMed Central: 34. doi:10.1186/1478-4505-12-34.

Orton, Lois, Ffion Lloyd-Williams, David Taylor-Robinson, Martin O’Flaherty, and Simon Capewell. 2011. "The Use of Research Evidence in Public Health Decision Making Processes: Systematic Review.” PLoS ONE 6 (7). doi:10.1371/journal.pone.0021704.

Paine Cronin, Gemma, and Mastoera Sadan. 2015. "Use of Evidence in Policy Making in South Africa: An Exploratory Study of Attitudes of Senior Government Officials.” African Evaluation Journal 3 (1): 10-pages. doi:10.4102/aej.v3i1.145. 
Parkhurst, Justin. 2017. The Politics of Evidence: From Evidence-Based Policy to the Good Governance of Evidence. Taylor \& Francis. doi:10.4324/9781315675008.

Parsons, W. 2002. "From Muddling Through to Muddling Up - Evidence Based Policy Making and the Modernisation of British Government.” Public Policy and Administration 17 (3): 43-60. doi:10.1177/095207670201700304.

Radaelli, Claudio M. 1995. "The Role of Knowledge in the Policy Process.” Journal of European Public Policy 2 (2). Taylor \& Francis Group : 159-83. doi:10.1080/13501769508406981.

Results For America. 2016. "Federal Invest In What Works Index (2016).” Washington DC. http://www.results4america.org/wp-content/uploads/2016/04/2016-Federal-IndexFINAL.pdf.

Rosella, Laura C, Kumanan Wilson, Natasha S Crowcroft, Anna Chu, Ross Upshur, Donald Willison, Shelley L Deeks, et al. 2013. "Pandemic H1N1 in Canada and the Use of Evidence in Developing Public Health Policies--a Policy Analysis.” Social Science \& Medicine (1982) 83. Elsevier Ltd: 1-9. doi:10.1016/j.socscimed.2013.02.009.

Sarewitz, Daniel. 2009. “The Rightful Place of Science.” Issues in Science and Technology 25 (4): 89-94.

Schmidt, Vivien A. 2013. "Democracy and Legitimacy in the European Union Revisited: Input, Output and 'Throughput.” Political Studies 61 (1): 2-22. doi:10.1111/j.14679248.2012.00962.x.

Stone, Deborah. 2002. Policy Paradox: The Art of Political Decision-Making. 2nd revise. New York: W. W. Norton \& Company.

Vasileiou, Konstantina, Julie Barnett, and Terry Young. 2012. "The Production and Use of Evidence in Health Care Service Innovation : A Qualitative Study." Evaluation \& the Health Professions 36 (1): 93-105. doi:10.1177/0163278712449622.

Weiss, C. H. 1979. “The Many Meanings of Research Utilization.” Public Administration Review 39 (5): 426-31.

What Works Network. 2014. "What Works? Evidence for Decision-Makers.” London. https:/www.gov.uk/government/uploads/system/uploads/attachment_data/file/378038/ What_works_evidence_for_decision_makers.pdf.

Wilkinson, Katy. 2011. "Organised Chaos: An Interpretive Approach to Evidence-Based Policy Making in Defra.” Political Studies 59: 959-77. doi:10.1111/j.14679248.2010.00866.x.

Wilsdon, James, B Wynne, and J Stilgoe. 2005. "The Public Value of Science: Or How to Ensure That Science Really Matters.” Demos. https://www.demos.co.uk/files/publicvalueofscience.pdf.

Zardo, Pauline, Alex Collie, and Charles Livingstone. 2014. "External Factors Affecting Decision-Making and Use of Evidence in an Australian Public Health Policy Environment.” Social Science and Medicine 108. Elsevier Ltd: 120-27. doi:10.1016/j.socscimed.2014.02.046. 